NBSIR 82-2504

\title{
Effects of Crack Growth on the Load-Displacement Characteristics of Precracked Specimens Under Bending
}

U.S. DEPARTMENT OF COMMERCE

National Bureau of Standards

National Measurement Labcratcry

Center for Materials Science

Fracture and Deformation Division

r/ashington, DC 20234

Mav 1982

\section{Frepared for}

Department of Energy

Advanced Research \& Technology Development

$-Q C \longrightarrow$ Energy Materials Program

ngton, DC 20545 



\title{
EFFECTS OF CRACK GROWTH ON THE \\ LOAD-DISPLACEMENT CHARACTERISTICS \\ OF PRECRACKED SPECIMENS UNDER \\ BENDING
}

JUL $7 \quad 1982$

T.-J. Chuang, E.R. Fuller, Jr., R. J. Fields, and L. Chuck

\begin{abstract}
U.S. DEPARTMENT OF COMMERCE
National Bureau of Standards

National Measurement Laboratory

Center for Materials Science

Fracture and Deformation Division

Washington, DC 20234
\end{abstract}

May 1982

\section{Prepared for}

Department of Energy

Advanced Research \& Technology Development

Fossil Energy Materials Program

Washington, DC 20545

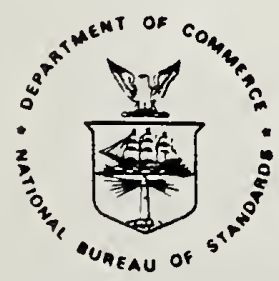

U.S. DEPARTMENT OF COMMERCE, Malcolm Baldrige, Secretary

NATIONAL BUREAU OF STANDARDS, Ernest Ambler, Director 



\title{
Effects of Crack Growth on the Load-displacement Characteristics of Precracked Specimens under Bending
}

T.-J. Chuang, E. R. Fuller, Jr., R. J. Fields and L. Chuck

\author{
Fracture and Deformation Division \\ National Bureau of Standards \\ Washington, DC 20234
}





\section{ABSTRACT}

A critical evaluation of the feasibility of obtaining crack growth parameters from bend tests is presented. First derived are the governing differential equations which characterize the time-history of bend test parameters for a given elastic material exhibiting power law crack growth behavior. A numerical solution scheme is then developed which is capable of solving the initial value problem, thus quantitatively assessing the influence of crack growth on the load-displacement output. The results of this analysis indicate that for high $\mathrm{N}$ materials (where $\mathrm{N}$ is the exponent in the power law crack growth equation) the flexural test method gives a broad error band in $\mathrm{N}$ prediction and hence is not a reliable technique. However, it can be used by a designer to quickly screen the new materials with high $\mathrm{N}$ values which are potential candidates for structural application. 


\section{INTRODUCTION}

Due to practical limitations to the technique of uniaxial tension test (such as difficulty in setting up the test fixture and gripping the specimen), flexural tests (e.g. three and four point bend tests) are widely adopted as alternative methods for obtaining the fracture parameters of brittle materials at elevated temperatures. ${ }^{1-3}$ In a typical bending test, a specimen is first precracked at the bottom edge of the midspan, enclosed in a furnace and then loaded by a mechanical testing machine in a pure flexural manner. Generally, the crosshead of the loading machine is kept at a slow constant displacement rate. Total load applied to the specimen is recorded continuously on a chart as a function of time. Under certain conditions, particularly those at high temperatures, nominally elastic specimens exhibit nonlinear load-displacement curves. This nonlinearity has been attributed to stable crack growth in the specimen. ${ }^{1-4}$ Since time is directly related to loadpoint displacement at a given crosshead speed, these nonlinear load vs. displacement curves contain information from which stable crack growth parameters can be deduced to give lifetime prediction. Assuming that the non-linearity of the load-displacement curve is due wholly to the subcritical crack growth without plastic deformation, several researchers $1,3,4$ have developed general procedures by which the crack growth kinetic law of the specimen can be extracted.

A question arises as to the accuracy of this resulting kinetic law for slight variations in the load-displacement curve unavoidably introduced by the chart recording system or other sources of error. 
This is an important issue as it may critically determine the applicability of this testing methodology. We believe, in order to resolve this issue, that a sensitivity analysis of the relation which maps curves of load-displacement ( $P$ vs $\delta$ ) to crack growth law (U vs $K_{I}$ ) is required. In what follows, we carry out such an analys is by numerically generating load-displacement curves for various crack growth laws. By varying the crack growth law, we can determine how sensitively the load-displacement curve reflects changes in crack growth behavior.

To perform the above sensitivity analysis, we have deduced a general method of solving the time-dependent problem of predicting the load-displacement curve for a given crack growth law. In Section II, a system of coupled ordinary differential equations is derived which characterizes the whole problem. Then a computer program which employs the Runge-Kutta numerical scheme is developed to solve for all relevant parameters as functions of displacement (or time). Using this program, the load-displacement solution as well as solutions for other relevant parameters are presented in Section III for a typical case. Further, with the availability of this program, it becomes possible to evaluate the effects of variation in crack growth parameters on load-displacement characteristics. Section IV discusses several important aspects of those influences.

Also, as a byproduct of the current analysis, the accuracy of fracture toughness $\left(\mathrm{K}_{\mathrm{IC}}\right.$ ) determinations can be assessed. In general, maximum load and maximum stress intensity do not coincide in time, as 
will be shown later. Consequently, the conventional method of computing $\mathrm{K}_{\mathrm{IC}}$ in terms of peak load may lead to an erroneous result.

\section{Analysis}

In this section, a detailed derivation of the control equations leading to solutions of the initial value problem is presented for a class of materials exhibiting a power law relationship between crack velocity $(u)$ and stress intensity factor $\left(\mathrm{K}_{\mathrm{I}}\right)$. In this regard, the following basic assumptions are made in order to simplify the analysis:

(1) the displacement rate, $\dot{\delta}$, is kept constant at all times. This assumption is consistent with the conditions under which a typical dynamic fatigue test is carried out; (2) the plastic deformation of the bulk is less significant than its elastic counterpart and the nonlinear behavior is due primarily to stable crack growth emanating from the existing notch; (3) the driving "force" for the crack extension is derived from the strain energy released in the near notch tip region rather than from diffusional dissipation of energy in the case of long term creep tests ${ }^{5}$; (4) for the sake of simplicity it is assumed that the contribution of compliance from the loading system is negligible so that the output of the experiment is a true curve. (Realistically, a true curve for the specimen can always be obtained by subtracting the system's compliance from the gross curve. ${ }^{3}$ On the other hand, the analysis could be extended to handle the gross output directly including the machine's compliance); (5) the notch is assumed to be sharp and straight through, although the solution scheme is developed in a general 
way and is thus capable of solving other crack geometries, including the chevron notch.

\subsection{Problem Definition}

Let us consider a notched beam of rectangular cross-section (width $B \times$ height $W$ ) under a load $P$ applied in a four-point bend fashion as illustrated in Fig. 1. Temperature is held constant throughout the test. It is assumed that a kinetic law of the following form adequately describes the subcritical crack growth behavior of the material:

$$
u=u_{\max }\left(K_{I} / K_{I C}\right)^{N} \text { for } K_{t h} \leq K_{I}<K_{I C}
$$

Here $U$ is the crack tip velocity ( $\equiv d a / d t$, crack length a and time $t$ ); $K_{I}$ is the applied stress intensity in the opening mode; $U_{\max }$ is the critical velocity at which rapid propagation occurs and $\mathrm{N}$ is the power law crack growth exponent, $K_{I C}$ is the fracture toughness, $K_{t h}$ is the threshold $\mathrm{K}_{\mathrm{I}}$ below which no crack growth can take place. The last four parameters are presumed to be the material's intrinsic properties. Thus, by definition,

$$
u=0 \quad \text { when } \quad K_{I}<K_{t h}
$$

and

$$
U=\text { infinity (indeterminate) if } K_{I} \geq K_{I C}
$$

Fig. 2 demonstrates a typical $U-K_{I}$ relationship on a logarithmic scale. A set of data for a typical ceramic material is also plotted for the sake of comparison. Eq. 1-3 are the fundamental equations on which the present analysis is based. Note that by setting different values of $K_{t h}$ 
and $K_{I C}$, those equations are capable of representing a wide range of crack growth behaviors. Now, if the notched specimen is loaded in pure bending at a constant crosshead speed such that the load-point displacement is in direct proportion to time, then

$$
\delta=\dot{\delta} t
$$

where $\dot{\delta}$ is the constant loading rate which is controllable. The problem is to find the time history of the applied load $P$ and other important variables under such arrangements.

\subsection{Derivation of Governing Equations}

In the case of a pure bend test as illustrated in Fig. 1 the crack tip stress intensity factor, $K_{I}$, can be related to the applied load $\mathrm{P}$, crack length a and other geometric constants by the following expression: ${ }^{6}$

$$
K_{I}=\frac{3}{2} \frac{P(L-\ell)}{B W^{3 / 2}} Y\left(\frac{a}{W}\right)
$$

where $L$ and $\ell$ are the major and minor spans respectively (see Fig. 1) and $Y$ is a function depending only on the normalized crack length. A typical form for the expression of $Y$ is 6

$$
Y(X)=\left(2 \tan \left(\frac{\pi x}{2}\right)\right)^{\frac{3}{2}}\left[0.923+0.199(1-\sin (\pi x / 2))^{4}\right] / \cos (\pi x / 2)
$$

Eq. (5b) is claimed to have an accuracy within $\pm \frac{1}{2} \%$ of the exact value for all crack lengths $\left(0 \leq \frac{a}{W} \leq 1\right)$. Various expressions for $Y$ other than 
Eq. (5b) are also available which yield different degrees of accuracy. ${ }^{7}$ In any event, any form of $Y$ can be handled and Eq. (5b) will be used hereafter for sake of demonstration.

The compliance $C$ of the beam specimen is defined at any time by

$$
C \equiv \delta / P
$$

where $\delta$ is the recorded load-point displacement. Now, since we assume the energy release rate $G$ is in the form of strain energy released in the crack tip zone, the following equality can be established:

$$
G=K_{I}^{2} / E^{\prime}=\frac{P^{2}}{2 B} \frac{d C}{d a}
$$

where $E^{\prime}$ is the effective Young's modulus $\left(E^{\prime}=E\right.$ for plane stress conditions; and $E^{\prime}=E /\left(1-v^{2}\right)$ for the plane-strain case, $v$ is Poissons ratio).

Eqs. (1), (4-7) form the control equations of the time-dependent problem for the unknown variables a, C, $K_{I}$ and $P$. However, after a careful study of this system of equations, it is found that only two dependent variables are needed to fully characterize the problem. Mathematically, this means that two nontrivial equations can be derived from these five control equations. For example, either $\mathrm{K}_{\mathrm{I}}$ and a or $\mathrm{C}$ and a can be chosen as a pair of dependent variables; but we found the latter pair will give more accurate results based on the numerical solution scheme, because a numerical integration inside each solution loop can be eliminated in this case. Furthermore, it is desirable for 
the sake of numerical solution to derive these two equations in a nondimensional form.

Let a bar on the top of a parameter be denoted as its counterpart in the nondimensional version. We can identify the specimen height $W$ as a normalization factor for length and $K_{I C}$ for $K$ such that

$$
\begin{aligned}
& \bar{\delta}=\delta / \mathrm{W} ; \overline{\mathrm{B}}=\mathrm{B} / \mathrm{W} ; \overline{\mathrm{a}}=\mathrm{a} / \mathrm{W} \\
& \overline{\mathrm{K}}=\mathrm{K}_{\mathrm{I}} / \mathrm{K}_{\mathrm{IC}}
\end{aligned}
$$

To choose normalizing parameters for $\mathrm{C}$ and $\mathrm{P}$, a criterion is found which enables the expression for $\mathrm{K}$ in $\mathrm{Eq}$. (5a) to be translated to the following simple form in the nondimensional version

$$
\overline{\mathrm{K}}=\overline{\mathrm{P}} \mathrm{Y}(\overline{\mathrm{a}})
$$

if we define

$$
C *=\frac{3}{2}((\mathrm{~L}-\ell) / \mathrm{B}) /\left(\mathrm{K}_{\mathrm{IC}} \sqrt{\mathrm{W}}\right)
$$

and

$$
P *=W / C *=\frac{2}{3}(B /(L-\ell)) W^{3 / 2} K_{I C}
$$

such that $\overline{\mathrm{C}}=\mathrm{C} / \mathrm{C}^{*}$ and $\overline{\mathrm{P}}=\mathrm{P} / \mathrm{P}^{*}$.

Now, with the well-defined nondimensional system, we can derive the required equations. First, the kinetic law of crack growth (Eq. (1)) reads

$$
\frac{d a}{d t}=U_{\max } \bar{K}^{N}
$$

if the applied $K_{I}$ falls in $\left[K_{t h}, K_{I C}\right]$. But $d t=d \delta / \dot{\delta}$ according to Eq. (4). Hence 


$$
\dot{\delta} \frac{\mathrm{da}}{\mathrm{d} \delta}=\dot{\delta} \frac{\mathrm{d} \overline{\mathrm{a}}}{\mathrm{d} \bar{\delta}}=u_{\max } \overline{\mathrm{K}}^{\mathrm{N}}
$$

or

$$
\frac{\mathrm{d} \overline{\mathrm{a}}}{\mathrm{d} \bar{\delta}}=\beta \overline{\mathrm{K}}^{\mathrm{N}}
$$

where $\beta \equiv u_{\max } / \dot{\delta}$. After substitution of $\overline{\mathrm{K}}=\overline{\mathrm{P}} \mathrm{Y}=(\bar{\delta} / \overline{\mathrm{C}}) \mathrm{Y}$, this equation finally becomes

$$
\frac{\mathrm{d} \bar{a}}{\mathrm{~d} \bar{\delta}}=\beta\left(\frac{\delta}{\bar{c}}\right)^{N} Y^{N}(\bar{a})
$$

This is a first order nonlinear differential equation for $\bar{a}$ as a function of $\bar{\delta}$.

Next, the expression of the strain energy release rate G, Eq. (7), can be used to derive another control equation. We rewrite $\mathrm{dC} / \mathrm{da}$ and Eq. (7) respectively in the following way

$$
\frac{\mathrm{dC}}{\mathrm{da}}=\frac{\mathrm{C}^{*}}{\mathrm{~W}} \frac{\mathrm{d} \overline{\mathrm{C}}}{\mathrm{d} \overline{\mathrm{a}}}=\frac{\mathrm{C}^{*}}{\mathrm{~W}}\left(\frac{\mathrm{d} \overline{\mathrm{C}}}{\mathrm{d} \bar{\delta}}\right) /\left(\frac{\mathrm{d} \overline{\mathrm{a}}}{\mathrm{d} \bar{\delta}}\right)
$$

and

$$
\frac{d C}{d a}=\frac{2 B}{E^{\prime}}\left(\frac{K}{P^{2}}\right)^{2}=\frac{2 B}{E^{\prime}}\left(K_{I C} C^{*} P^{*}\right)^{2}
$$

Combination of these two equations result in

$$
\left(\frac{\mathrm{C}^{*}}{\mathrm{~W}}\right)\left(\frac{\mathrm{d} \overline{\mathrm{C}}}{\mathrm{d} \bar{\delta}}\right) /\left(\frac{\mathrm{d} \overline{\mathrm{a}}}{\mathrm{d} \bar{\delta}}\right)=\frac{2 \mathrm{~B}}{\mathrm{E}^{\prime}}\left(\mathrm{K}_{\mathrm{IC}} \mathrm{Y}^{* \mathrm{P}^{*}}\right)^{2}
$$

or

$$
\frac{\mathrm{d} \bar{c}}{d \bar{\delta}}=\frac{2 B W}{E^{\prime} C^{*}} \frac{K_{I C}^{2} Y^{2}}{\left(P^{*}\right)^{2}} \frac{d \bar{a}}{d \bar{\delta}}
$$




$$
=\left(\frac{2 \mathrm{BW}}{\mathrm{E}^{\prime} \mathrm{C}^{*}\left(\mathrm{P}^{*} \mathrm{P}^{*}\right)^{2}}\right)\left(\frac{\beta}{\bar{C}}\right)^{\mathrm{N}} \mathrm{Y}^{\mathrm{N}+2}
$$

after substitution of $\mathrm{d} \bar{a} / \mathrm{d} \bar{\delta}$ from Eq. (11). This equation can be rewritten in the following simple form if we substitute the expressions for $C^{*}$ and $P^{*}$ from Eqs. $(9-10)$

$$
\frac{\mathrm{d} \overline{\mathrm{C}}}{\mathrm{d} \bar{\delta}}=3 \alpha \beta\left(\frac{\bar{\delta}}{\overline{\mathrm{C}}}\right)^{\mathrm{N}} \mathrm{Y}^{\mathrm{N}+2}
$$

where $\alpha=[(I-\ell) / W]\left(K_{I C} / E^{\prime} \sqrt{W}\right)$

\subsection{Initial conditions}

We have derived the necessary control equations for the unknown variables $\bar{C}$ and $\bar{a}$ as a function of $\bar{\delta}$, Eqs. (11-12), which are coupled differential equations. Clearly, the initial conditions $\bar{c}(0)$ and $\bar{a}(0)$ are required in order to obtain a unique solution.

At the onset of the test when $t=0, \bar{\delta}=0$ and

$$
\overline{\mathrm{a}}=\overline{\mathrm{a}}(0)=\overline{\mathrm{a}}_{0}
$$

where $\bar{a}_{0}$ is the normalized initial crack length, $a_{0} / W$, which is known and controllable.

To evaluate the initial compliance, we note that in general the elastic compliance of a cracked beam is dependent on the crack length, $a$, and is a sum of two contributions: $C_{0}$, the compliance of an equivalent unnotched beam and $C(a)$, the additional compliance due to the presence of a crack with a length a. The expression for $C_{0}$ can be 
derived from the conventional strength of materials method. ${ }^{8}$ The result is a function of cross-section, major and minor spans, and effective elastic modulus.

$$
C_{0}=\frac{1}{4}(L-\ell)^{2}(L+2 \ell) / B W^{3} E^{\prime}
$$

The increased compliance due to the existence of a crack of length a canbe found by integration of Eq. (7) to give

$$
C(a)=\frac{9}{2} \frac{(L-l)^{2}}{E^{\prime} B W^{2}} \int_{0}^{a / w}[Y(x)]^{2} d x
$$

Thus, the true nondimensional compliance at the onset of the test $(\bar{\delta}=0)$ is the sum of Eq. (14) and (15)

$$
\bar{C}(0)=\left[C C_{0}+C\left(a_{0}\right)\right] / C^{*}=\frac{\alpha}{6} \frac{(L+2 l)}{w}+3 \alpha \int_{0}^{\bar{a}}[Y(x)]^{2} d x
$$

Eqs. (11) and (12) together with the initial conditions Eq. (13) and (16) constitute a well defined initial value problem. Unique solutions for a typical case are to be pursued in the subsequent section.

\section{Numerical Solutions}

The nonlinear first order differential equations, Eqs. (11) and (12) for the unknown variables $\bar{a}$ and $\bar{c}$ are solved numerically in this section as a function of $\bar{\delta}$ by a Runge-Kutta method with the initial 
conditions given by Eqs. (13) and (16). Note that all parameters involved are dimensionless. Descriptions of the solution methodology and how the computer program is constructed to solve this initial value problem are given in the Appendix. Fig. 3 shows a typical set of solutions for the normalized crack length, applied load, stress intensity and compliance as a function of normalized displacement using a typical input data compiled in Table $I$.

In general, if the initial crack size is shallow $\left(a_{0}<<\right)$ and the loading rate is slow $\left(\dot{\delta}<u_{\max }\right)$ then the load-displacement records will show a complete curve without abrupt interruption and the entire test period can be divided into three stages: (1) no crack growth period in which the crack front remains stationary, resulting in linear elastic behavior, (2) rapid crack growth period during which the peak 1.oad and maximum stress intensity occur and finally (3) a slow crack growth period when an elastic hinge forms at the remaining uncracked ligament. In terms of $\bar{\delta}$, the transition points separating those three stages would be at $\bar{\delta} \times 10^{4} \sim 1.0$ and 3.0 respectively in reference to Fig. 3 . Of course, any change in the crack growth parameters (e.g. $U_{\max }, K_{\text {th }}$ etc.) would cause these boundary lines to shift.

In the initial stage when the applied load is sufficiently small such that $K<K_{t h}$ a stationary crack tip results. This means that the specimen behaves in a linear elastic manner: both compliance and crack length remain fixed at their initial values; the applied load increases linearly with increasing displacement, as does the stress intensity so long as its magnitude stays below $K_{t h}$. 
As the test proceeds with increasing load, a point is reached where $\mathrm{K}$ has increased to its threshold level $\mathrm{K}_{\text {th }}$ and the displacement is

$$
\bar{\delta}=K_{t h} \bar{C}_{0} / K_{I C} Y\left(\bar{a}_{0}\right)
$$

where $\bar{C}_{0}$ is the initial compliance given by Eq. (16). Then the crack starts to grow according to the governing kinetic law of Eq. (1) and the second stage ensues. In this region, the crack tip first moves very slowly and then begins to take off. This crack growth behavior is solely responsible for causing both $\overline{\mathrm{P}}$ and $\overline{\mathrm{K}}$ curves to become nonlinear, reach their peaks and then to decrease. This phenomenon can be easily explained if we write the slope of the $\bar{P}$ vs $\bar{\delta}$ curve in the following way

$$
\frac{\mathrm{d} \overline{\mathrm{P}}}{\mathrm{d} \bar{\delta}}=\frac{\overline{\mathrm{P}}}{\bar{\delta}}\left(1-\overline{\mathrm{P}} \frac{\mathrm{d} \overline{\mathrm{C}}}{\mathrm{d} \bar{\delta}}\right)
$$

It becomes clear then that there are two components contributing to the slope: the first term is just the stiffness of the beam and the second term represents a decreased slope which is attributable to the increase of compliance due to crack growth. Note that in the first stage, $\overline{\mathrm{C}}=$ const $\left(=\overline{\mathrm{C}}_{0}\right)$ so that the second term vanishes and $\mathrm{d} \overline{\mathrm{P}} / \mathrm{d} \bar{\delta}=\overline{\mathrm{P}} / \bar{\delta}$ or $\overline{\mathrm{P}}=$ (const) $\bar{\delta}$, a consistent result of linear behavior. In the second stage of rapid crack growth, $d \bar{C} / d \bar{\delta}$ increases rapidly from zero causing $d \bar{P} / d \bar{\delta}$ to deviate from its linearity. The peak load, $\overline{\mathrm{P}}_{\max }$ is achieved when the right side of Eq. (18) vanishes, or

$$
\overline{\mathrm{P}}_{\max }=\left(\frac{\mathrm{d} \overline{\mathrm{C}}}{\mathrm{d} \bar{\delta}}\right)_{\bar{\delta}=\bar{\delta}}^{-1}
$$


where $\bar{\delta}^{*}$ is the normalized $\delta$ at which $\overline{\mathrm{P}}=\overline{\mathrm{P}}_{\max }$ (see Fig. 6). With increasing displacement the slope becomes negative, resulting in a rapid decrease of load. Note that the peak load and peak stress intensity do not coincide in time; rather the former always occurs earlier than the latter. This can be supported by the following argument. It was shown in Eq. (8) that $\overline{\mathrm{K}}$ consists of two competing multiplicative factors, namely the applied load and the instantaneous crack length. Immediately after the maximum load is reached, the decrease of $\bar{K}$ attributable to reducing $\overline{\mathrm{P}}$ is far less than the increase of $\overline{\mathrm{K}}$ by crack growth so that the true $\overline{\mathrm{K}}$ values continue to increase until the former factor outweighs the latter, at which point the peak $\overline{\mathrm{K}}$ is observed. It has been conventional to compute $K_{I C}$ based on the measured $P_{\max }$. This is correct only if there is no subcritical crack growth in the entire test period so that peak load coincides with peak $\mathrm{K}$ in time. We have witnessed that this practice will give a nonconservative estimate of $\mathrm{K}_{\mathrm{IC}}$ which is always higher than the true value, if stable crack growth does indeed take place.

Finally, in the third stage after the crack length has grown to $\approx 95$ pct of the specimen's height, a "hinge" mechanism forms where the uncracked ligament is so small that it serves as a rotational hinge allowing continued displacement at exceedingly small loads. As a result, the applied load in this region has dropped to $<<2 \%$ of the peak load. Meanwhile, the compliance of the specimen increases exponentially (see Fig. 3). 
IV. Discussion

We have presented a typical set of complete time-history solutions of crack length, applied load, stress intensity and compliance for a four-point bend beam specimen from simultaneous differential equations for materials exhibiting power law crack growth. Realistically, there always exist some degrees of uncertainty in determining the crack growth parameters from a given set of crack growth ( $U$ vs $K_{I}$ ) data. This prompts a need to carry out a parametric study wherein the effects of variations in the crack growth parameters on the load-displacement records can be assessed. This study can be used to determine the applicability of the flexural test methods for a given material. The solution scheme developed in the preceding section makes such a study possible. In the following subsections, the behavior of load as well as other important variables will be analyzed individually by variation of crack growth parameters.

\subsection{Effect of Critical Velocity on Load-Displacement Curves}

In this study, the $\mathrm{P}-\delta$ curves are solved for several values of $U_{\max }$, while keeping the remaining parameters constant, as given in Table I. The results are shown in Fig. 4 where the three curves are seen to differ considerably in the rapid crack growth region (stage II). It is observed that there are no differences in the linear parts because linear elastic behavior governs and hence $U_{\max }$ plays no role in this region. Note that the peak load decreases as $U_{\max }$ increases. Indeed, in the nonlinear regime, the load at any given displacement also 
decreases as $U_{\max }$ increases. However, for a given material, $U_{\max }$ is an intrinsic property and hence must remain fixed. But the loading rate, $\dot{\delta}$, can be manually adjusted to give the same results, since it is the ratio of $U_{\max } / \dot{\delta}$ which characterizes the problem so that increasing $U_{\max }$ has the same effect as reducing $\dot{\delta}$. The implication is that by raising the loading rate, the peak load would be predicted to increase monotonically until it reaches a level corresponding to $\mathrm{K}_{\mathrm{IC}}$. At this point, a sharp drop in load-displacement curve will be observed and an incomplete curve will result. In contrast, the solutions given in Fig. 4 show complete curves because the loading rate applied in these cases is very slow, where $\mathrm{K}$ always remains below $\mathrm{K}_{\mathrm{IC}}$.

\subsection{Effect of Crack Growth Exponent (N) on Maximum Load}

The change in maximum load $\left(\mathrm{P}_{\max }\right)$ as a result of changing the crack growth exponent $(N)$ is studied in this subsection for $U_{\max }=10 \mathrm{~mm} / \mathrm{s}$ and other geometric and loading constants listed in Table I. For each value of $N$, the value of $P_{\max }$ can be obtained from the present work. To study the effect of changing $N$, a series of solution schemes has to be applied in a discrete manner in $N$. Hence we begin with $N=0$ and repeat the computer program, each time with the increment of $\Delta \mathrm{N}=0.5$ until the desired range of $\mathrm{N}$ is wholly covered. The program produced $\mathrm{P}_{\max }$ vs $\mathrm{N}$ curves for $0 \leqq N \leqq 50$. Fig. 5 shows the curves of $\overline{\mathrm{P}}_{\max }$ vs $N$ for $\overline{\mathrm{a}}_{0}=0.2$, 0.5 and 0.7 respectively. For comparison, the limiting values of $P_{\max }$ (i.e. the asymtotic value at which $N$ = infinity) are indicated for each curve. We found at $\mathrm{N}=50$, the maximum $\mathrm{N}$ we computed, $\overline{\mathrm{P}}_{\max }$ has arrived to $92 \%, 91 \%$ and $90 \%$ of their limiting values for $\bar{a}_{0}=0.2,0.5$ and 0.7 
respectively. The following two observations can also be made from Fig. 5: (1) for a given initial crack length, materials with higher $\mathrm{N}$ can sustain higher load although the increase of load levels off after $\mathrm{N}$ $>$ 20. (2) for a given material where $\mathrm{N}$ is fixed, a shallow initial cracked specimen can carry higher load; as can be seen the differences between the three curves corresponding to $\bar{a}_{0}=0.2,0.5$ and 0.7 are substantial.

\subsection{Effect of Crack Growth Exponent on Peak Load Decrement}

In carrying out a flexural test for a new material to ascertain its crack growth behavior, one often is confronted with a question as to whether the crack growth is observable from the output of the loaddisplacement records with a built-in inaccuracy (albeit a small percentage). In this regard, it may be useful to introduce a new parameter which can measure the degree of observability of crack growth. This new parameter, the peak load decrement, $R$, is defined as the percentage of deviation of stiffness at the peak load point on the P- $\delta$ curve from the initial stiffness, namely

$$
R(\text { pct })=\frac{1 / \bar{c}_{0}-1 / \bar{C}_{\ell}}{1 / \bar{C}_{0}} \times 100 \%=\left[1-\left(\bar{C}_{0} / \bar{C}_{\ell}\right)\right] \times 100 \%
$$

For physical interpretation of $R$, a schematic sketch of a loaddisplacement curve is shown in Fig. 6 . Here $\bar{\delta}^{*}$ is the nondimensional $\delta$ at which peak load occurs. The parameter $R$ can be expressed in terms of load by multiplying $\bar{\delta}^{*}$ on both numerator and denominator of the right side of Eq. (20) 
$R(p c t)=\frac{\overline{\mathrm{P}}_{\ell}-\overline{\mathrm{P}}_{\max }}{\overline{\mathrm{P}}_{\ell}} \times 100 \%$

We can interpret the physical meaning of $R$ in the following way. It is a measure of deviation of $\overline{\mathrm{P}}-\bar{\delta}$ curves from linearity. Thus, a higher value of $\mathrm{R}$ implies a heavier influence of crack growth on the $\mathrm{P}-\delta$ curves. For large R's, one can determine crack growth parameters accurately from these curves. On the contrary, low R-values would yield a wide range of uncertainty, for a slight variation in the $P-\delta$ curve. This can be easily envisioned in Fig. 7 where $R$ is plotted as a function of $\mathrm{N}$ for three different initial crack lengths. The same technique as described in Sec. 4.2 was employed to produce this figure. Other required parameters are held constant (see Table I). Suppose inertia of the motor driven mechanism combined with the width of the drawing pen results in $\pm 1 \%$ of confidence margin. For a material with a true value of $\mathrm{N}=10$, the possible range of $\mathrm{N}$ for $\overline{\mathrm{a}}_{\mathrm{o}}=0.5$ is from 8.5 to 11.5 according to Fig. 7. However, if true $\mathrm{N}$ increases to 25 , the range of observed $N$ would expand from 20 to 32 . This means that the prediction of $\mathrm{N}$ for a typical case shown here is subject to a great degree of uncertainty when $N>20$. Table II gives a list of true $N$ vs. its band range for $R= \pm 1 \%$. Also, as indicated by Fig. 7 , the confidence range seems to be insensitive to the initial crack length, although deep cracked specimens do yield higher values of $R$. Hence we are led to conclude that at least for the cases we studied, only low $\mathrm{N}$ materials yield meaningful results. For materials exhibiting high $N$ (say $N>20$ ) the bend test is not a good method to obtain crack growth parameters. 


\section{CONCLUDING REMARKS:}

We have presented here a general mathematical procedure to quantify the effect of crack growth on the load-displacement characteristics of elastic flexural specimens. By doing this, a critical assessment has been made of the feasibility of using bend test methods to obtain crack growth parameters by evaluating the relations between load-displacement and $U-K_{I}$ curves. In studying the effects of changing $U_{\max }$ and $\mathrm{N}$ on the P-o curves, we are able to determine the confidence margins of this methodology for a class of materials exhibiting power law crack growth behavior. It is concluded from this study that only for low $\mathrm{N}$ materials are the flexural test methods capable of making satisfactory predictions of crack growth behavior. When evaluation of high nominal $\mathrm{N}$ materials is attempted, this technique breaks down since it results in broad error bands. However, the merits of adopting bend tests remain in the ease of setup and load application and expedient to obtain the data. Hence, it is appropriate to use this method to prescreen new materials for the purpose of quickly selecting high $N$ materials which are superior for structural application.

Acknowledgement:

The authors thank $R$. de Wit for his help interfacing the FORTRAN program with the UNIVAC 1108 computer and its related plotting accessories. 


\section{References}

1. H. Hübner and W. Jillek, "Sub-critical crack extension and crack resistance in polycrystalline alumina", J. Mater. Sci. 12, [ ] 117-25 (1977).

2. D. Munz, R. T. Bubsey and J.L. Shannon, Jr., "Fracture Toughness Determination of $\mathrm{Al}_{2} \mathrm{O}_{3}$ Using Four-Point-Bend Specimens with Straight-Through and Chevron Notches", J. Am. Ceram. Soc. 63, [5-6] 300-305 (1980).

3. F. W. Kleinlein and H. Hubner, "The Evaluation of Crack Resistance and Crack Velocity From Controlled Fracture Experiments of Ceramic Bend Specimens" Fracture, Vol. 3, ICF4, Waterloo, Canada, June, 1977 .

4. R. J. Fields, E. R. Fuller, Jr., T.-J. Chuang, I. Chuck and K. Kobayashi, "Crack Growth in Sialon" in "Fracture Mechanics of Ceramics", Eds. R. C. Bradt, D. H. P. Hasselman, A.G. Evans and F. F. Lange.

5. T.-J. Chuang, "A Diffusive Crack-Growth Model for Creep Fracture", J. Am. Ceram. Soc. 65 [2] 93-103 (1982).

6. H. Tada, P. C. Paris and G. R. Irwin, "The Stress Analysis of Cracks Handbook" Del Research Corp., Hellertown, PA pp 2-14 (1973).

7. W. K. Wilson, "Stress Intensity Factors for Deep Cracks in Bending and Compact Tension Specimens", Engr. Frac. Mech. 2, [ ] 169-171 (1970).

8. S. Timoshenko "Strength of Materials" Part I, p. 159, 3rd Ed., D. Van Nostrand Co. Inc. (1955).

9. A. G. Evans, pp 373-96 in Ceramics for High-Performance Applications, Proceedings of the 2nd Army Materials Technology Conference, Hyannis, Massachusetts, November, 1973. 


\section{APPENDIX}

Numerical Solution Scheme in Solving the Initial Value Problem

As appeared in the text, a system of simultaneous differential equations of the following form for the unknown variables $C(\delta)$ and $a(\delta)$, where $\delta$ is independent variable, has to be solved:

$$
\begin{aligned}
& \frac{d c}{d \delta}=F(\delta, c, a) \\
& \frac{d a}{d \delta}=G(\delta, c, a)
\end{aligned}
$$

subject to the initial conditions

$$
\begin{aligned}
& c(0)=c_{0} \\
& a(0)=a_{0}
\end{aligned}
$$

where specific expressions for F, and $G$ are given by Eq. (11) and (12) respectively in the text.

This is a well defined initial value problem and unique solutions can be pursued by the conventional Runge-Kutta numerical solution scheme.

We begin the solution process with the initial point $\delta=\delta_{0}$ where $C$ $\left(\delta_{0}\right)$ and $a\left(\delta_{0}\right)$ are given by Eq. $(\mathrm{A}-1 \mathrm{C})$. Here $\delta_{0}$ is a reference point and hence can be arbitrarily set to zero. Now let the independent variable $\delta$ advances a step size $\Delta \delta$ to a new point $\delta_{0}+\Delta \delta$; the task is to compute the values of $C$ and a at this new point. In terms of equations, how can we compute $f$ and $g$ if we write 


$$
\begin{aligned}
& c\left(\delta_{0}+\Delta \delta\right)=c\left(\delta_{0}\right)+f \\
& a\left(\delta_{0}+\Delta \delta\right)=a\left(\delta_{0}\right)+g
\end{aligned}
$$

Let $f_{i}$ and $g_{i}(i=1, \ldots 4)$ be defined by the following equations

$$
\begin{aligned}
& f_{1}=\Delta \delta \cdot F\left(\delta_{0}, C_{0}, a_{0}\right) ; \\
& g_{1}=\Delta \delta \cdot G\left(\delta_{0}, C_{0}, a_{0}\right) \\
& f_{2}=\Delta \delta \cdot F\left(\delta_{0}+\Delta \delta / 2, C_{0}+f_{1} / 2, a_{0}+g_{1} / 2\right) ; \\
& g_{2}=\Delta \delta \cdot G\left(\delta_{0}+\Delta \delta / 2, C_{0}+f_{1} / 2, a_{0}+g_{1} / 2\right) \\
& f_{3}=\Delta \delta \cdot F\left(\delta_{0}+\Delta \delta / 2, C_{0}+f_{2} / 2, a_{0}+g_{2} / 2\right) ; \\
& g_{3}=\Delta \delta \cdot G\left(\delta_{0}+\Delta \delta / 2, c_{0}+f_{2} / 2, a_{0}+g_{2} / 2\right) \\
& f_{4}=\Delta \delta \cdot F\left(\delta_{0}+\Delta \delta, c_{0}+f_{3}, a_{0}+g_{3}\right) ; \\
& g_{4}=\Delta \delta \cdot G\left(\delta_{0}+\Delta \delta, c_{0}+f_{3}, a_{0}+g_{3}\right)
\end{aligned}
$$

then the Runge-Kutta scheme yields the following results for $f$ and $g$

$$
f=\frac{1}{6}\left(f_{1}+2 f_{2}+2 f_{3}+f_{4}\right)
$$

and

$$
g=\frac{1}{6}\left(g_{1}+2 g_{2}+2 g_{3}+g_{4}\right)
$$

Note that both $f_{i}$ and $g_{i}$ can be evaluated in sequence since both $f_{i}$ and $g_{i}$ depend on $\left(f_{i-1}, g_{i-1}\right)$. Once $f$ and $g$ are computed, the unknown variables $C$ and a at the new position of $\delta_{0}+\Delta \delta$ can be found from Eqs. $(A-2)$. The same procedure can be repeated to calculate $C\left(\delta_{0}+2 \Delta \delta\right)$ and $a\left(\delta_{0}+2 \Delta \delta\right)$ a step further at $\delta_{0}+2 \Delta \delta$ from the previously solved values of $C\left(\delta_{0}+\Delta \delta\right)$ and $a\left(\delta_{0}+\Delta \delta\right)$. This process can be continued until some criteria of termination of computation are satisfied and the whole initial value problem is solved.

A FORTRAN computer program was developed following the above described scheme. Fig. 8 shows the flow diagram associated with this 
program. In the first loop concerned with the linear region, we let $\delta$ increase monotonically with one step size $\Delta \delta$ at a time. In this loop, all new C's and a's remain unchanged at their original values, but both $P$ and $K$ increase linearly until $K=K_{t h}$ then the computation will jump to another loop where essentially the main task is to solve for $f$ and $g$. This process continues until either $\mathrm{K}=\mathrm{K}_{\mathrm{IC}}$ or $\mathrm{a}=\mathrm{H}$ then the computation will terminate and the whole solution is obtained.

In general, the smaller the $\Delta \delta$, the more accurate the solution that can be obtained for problems solved by Runge-Kutta scheme. But there is a drawback in which, as $\Delta \delta$ decreases, the cost of computation time increases exponentially. Specifically, in the case we considered, the convergence of this ordinary differential equation system has been assessed and the optimum size of $\Delta \delta$ has been identified to be $1 \times 10^{-4}$. It was found that a smaller step size would not increase the accuracy substantially although the computation time would increase rapidly. 
Table I. Geometrical and materials data adopted as input to solve the initial value problem

Parameter

Specimen's height, W(mm)

Specimen's width, B (mm)

Major span, L (mm)

Minor span, $\ell(\mathrm{mm})$

Loading rate, $\dot{\delta}(\mathrm{mm} / \mathrm{s})$

Integration step size $\Delta \bar{\delta}$

Normalized initial crack length $\bar{a}_{0}$

Effective Youngs modulus, E' (GPa)

Fracture toughness, $\mathrm{K}_{\mathrm{IC}}\left(\mathrm{MPa}^{\frac{3}{3}} \mathrm{~m}^{\frac{3}{2}}\right)$

Threshold $\mathrm{K}, \mathrm{K}_{\mathrm{th}}\left(\mathrm{MPa} \cdot \mathrm{m}^{\frac{1}{2}}\right)$

Crack growth parameters

$U_{\max }(\mathrm{mm} / \mathrm{s})$

$\mathrm{N}$
Value

9.964

4.14

40.0

10.0

$2.11 \times 10^{-4}$

$1 \times 10^{-6}$

0.2

360

4.0

0.4

10.0

6.0

Unless specified otherwise

Characteristic compliance, $C^{*}(\mathrm{~mm} / \mathrm{N})$

0.02722

Characteristic load, $\mathrm{P}^{*}(\mathrm{~N})$ 
Table II. List of band range in $\mathrm{N}$ vs $\mathrm{N}$ for a confidence margin of $\pm 1 \%$ in $R$.

\begin{tabular}{cc}
\hline $\mathrm{N}$ & Band Range in $\mathrm{N}$ \\
\hline 5 & $5.3 \sim 5.8$ \\
10 & $8.5 \sim 11.5$ \\
15 & $12.5 \sim 18$ \\
20 & $16 \sim 26$ \\
25 & $20 \sim 32$ \\
30 & $23.5 \sim 46$ \\
\hline
\end{tabular}




\section{Figure Captions}

Fig. 1. Geometry of a typical bend specimen with a sharp midspan crack.

Fig. 2. Schematic plots of $U=\mathrm{AK}_{I}{ }^{\mathrm{N}}$ for some typical ceramic materials.

Fig. 3. Typical time history solutions of crack length, applied load, stress intensity, and specimen's compliance as a function of load-point displacement.

Fig. 4. $P$ vs $\delta$ solutions showing the effect of varying $U_{\max }$.

Fig. $\dot{5}$. Plots of normalized peak load $\mathrm{P}_{\max }$ vs $\mathrm{N}$ for different initial crack lengths.

Fig. 6. Schematic sketch of P- $\delta$ curve for physical interpretation of the parameter $R$.

Fig. 7. Plots of $\mathrm{R}$ vs $\mathrm{N}$ for $\mathrm{a}_{0}=0.7,0.5$, and 0.2 respectively.

Fig. 8. Flow diagram of solving the initial value problem numerically by Runge-Kutta method. 


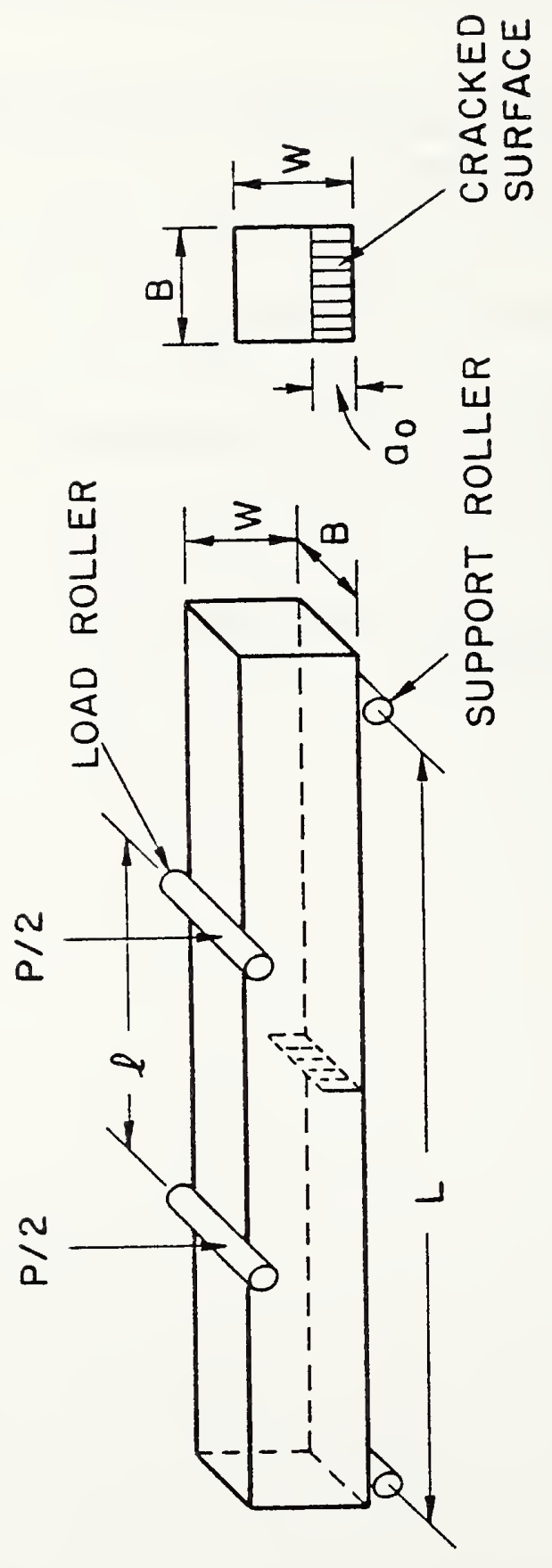




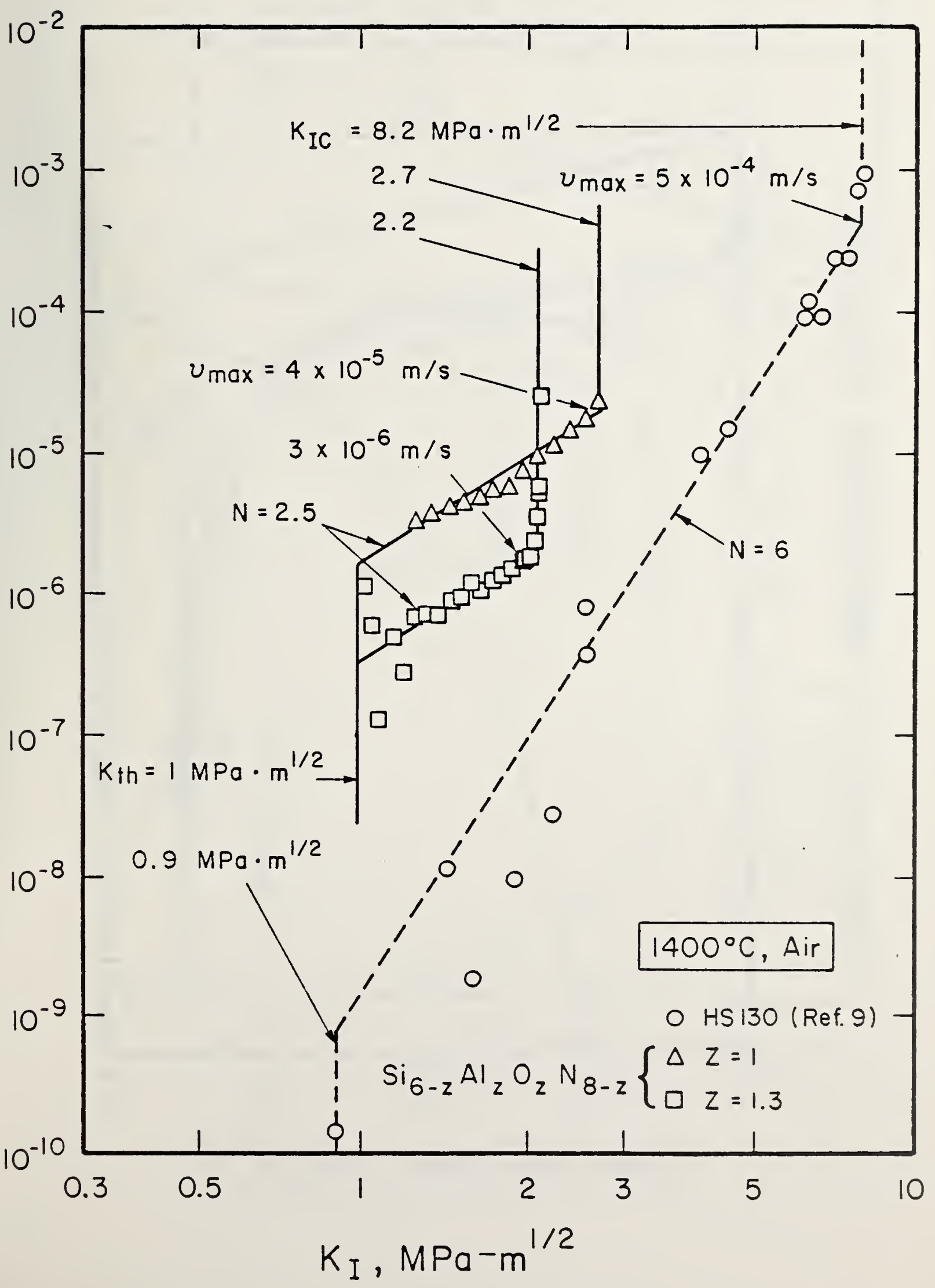




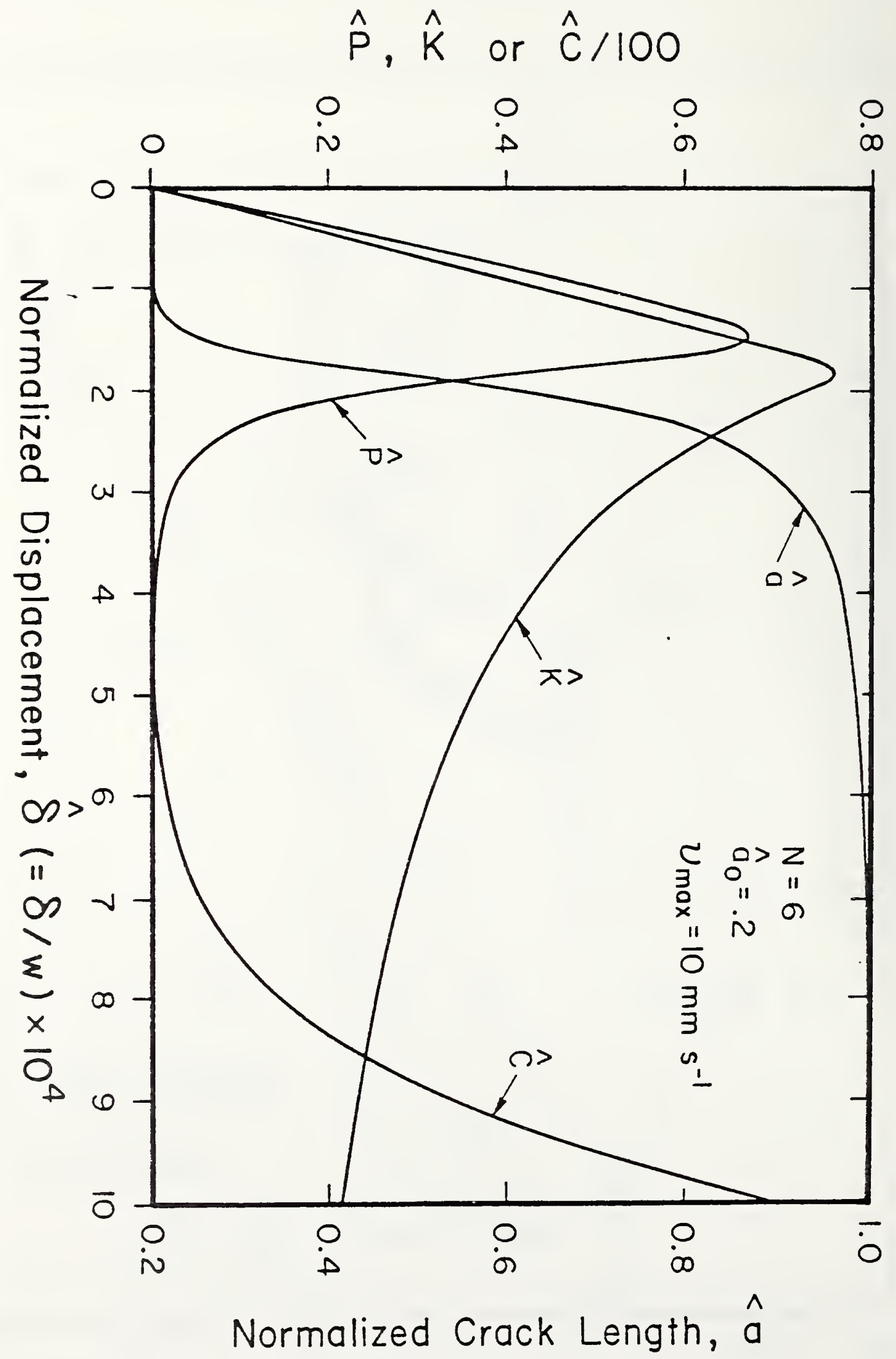




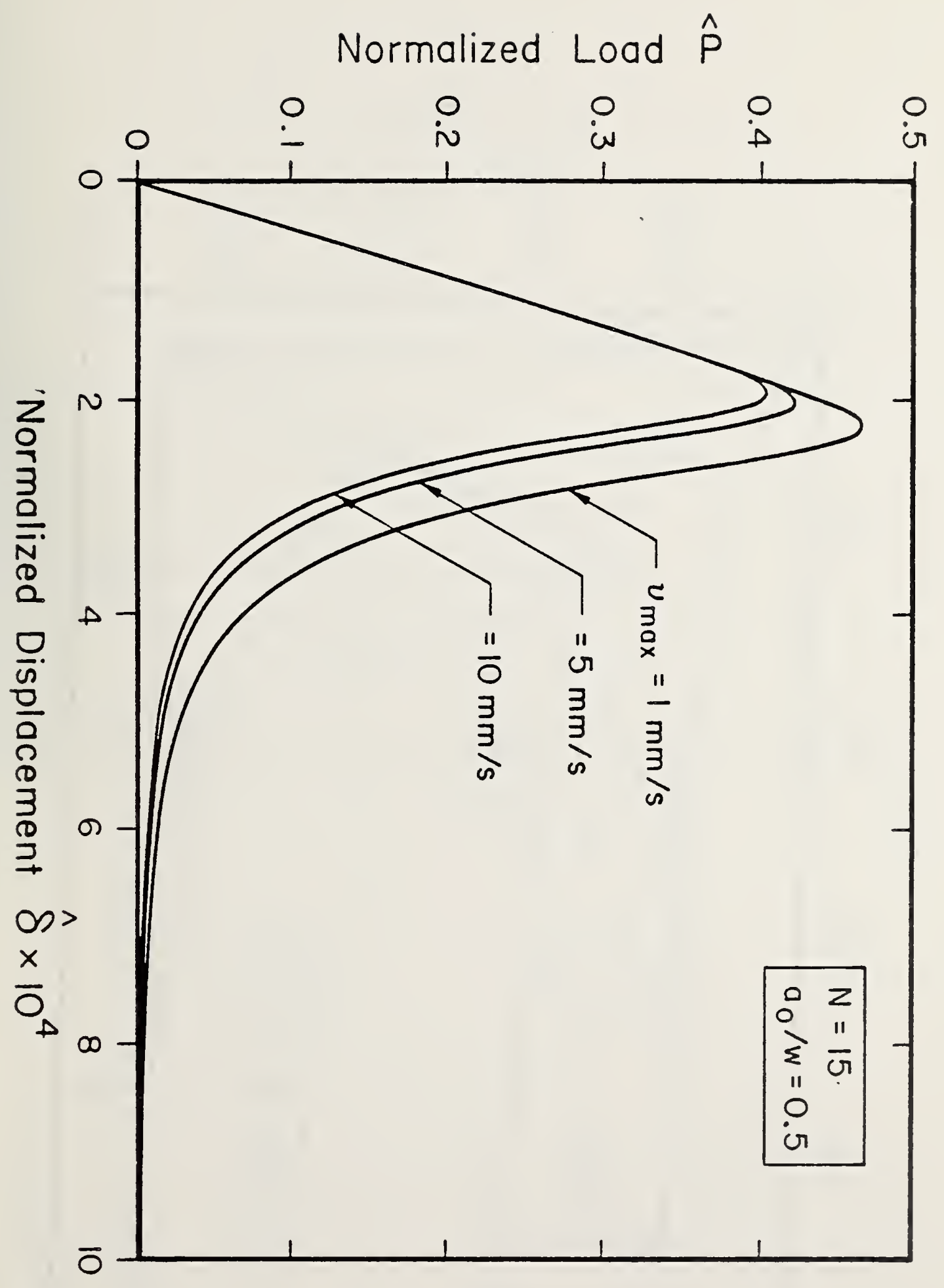




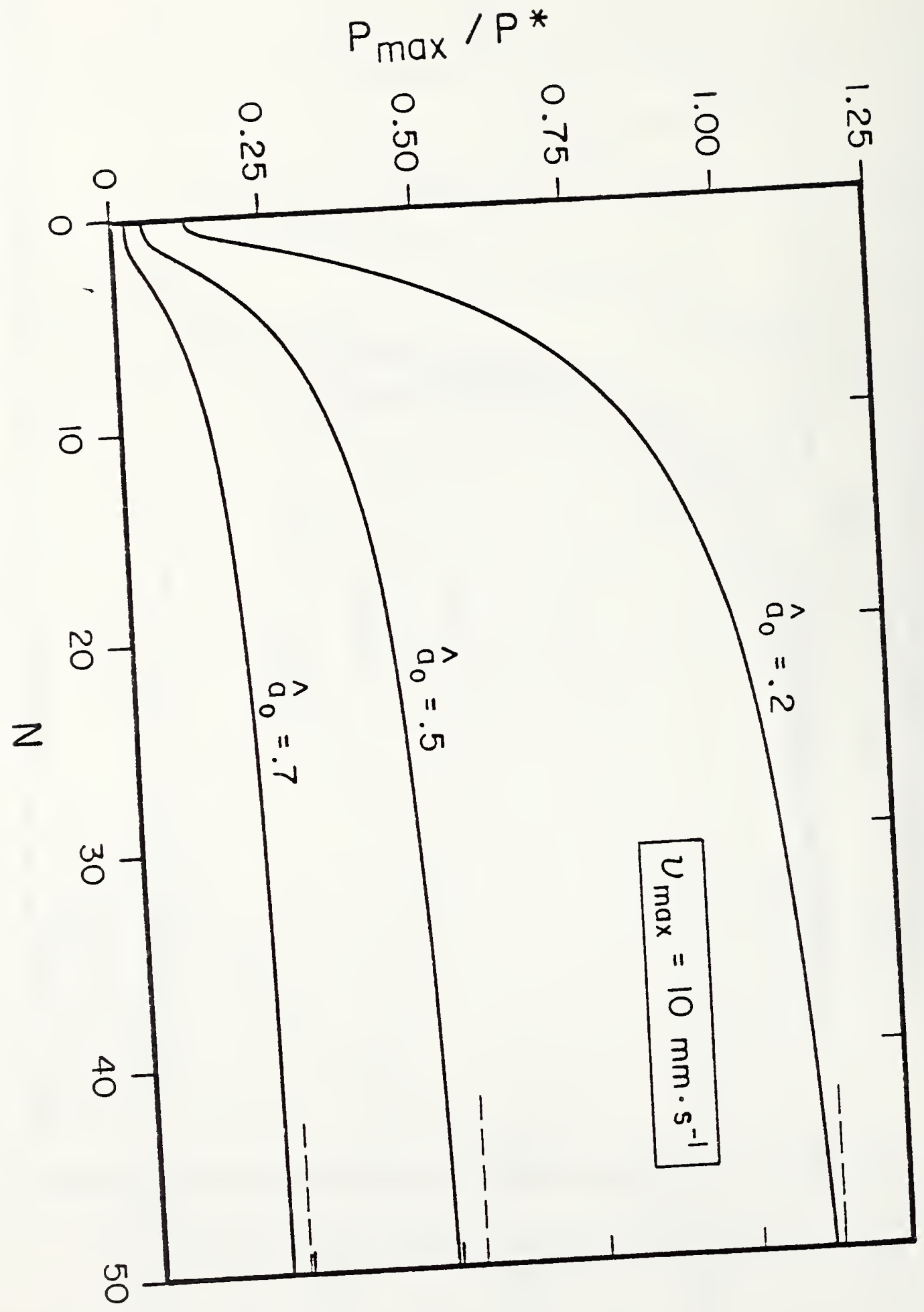




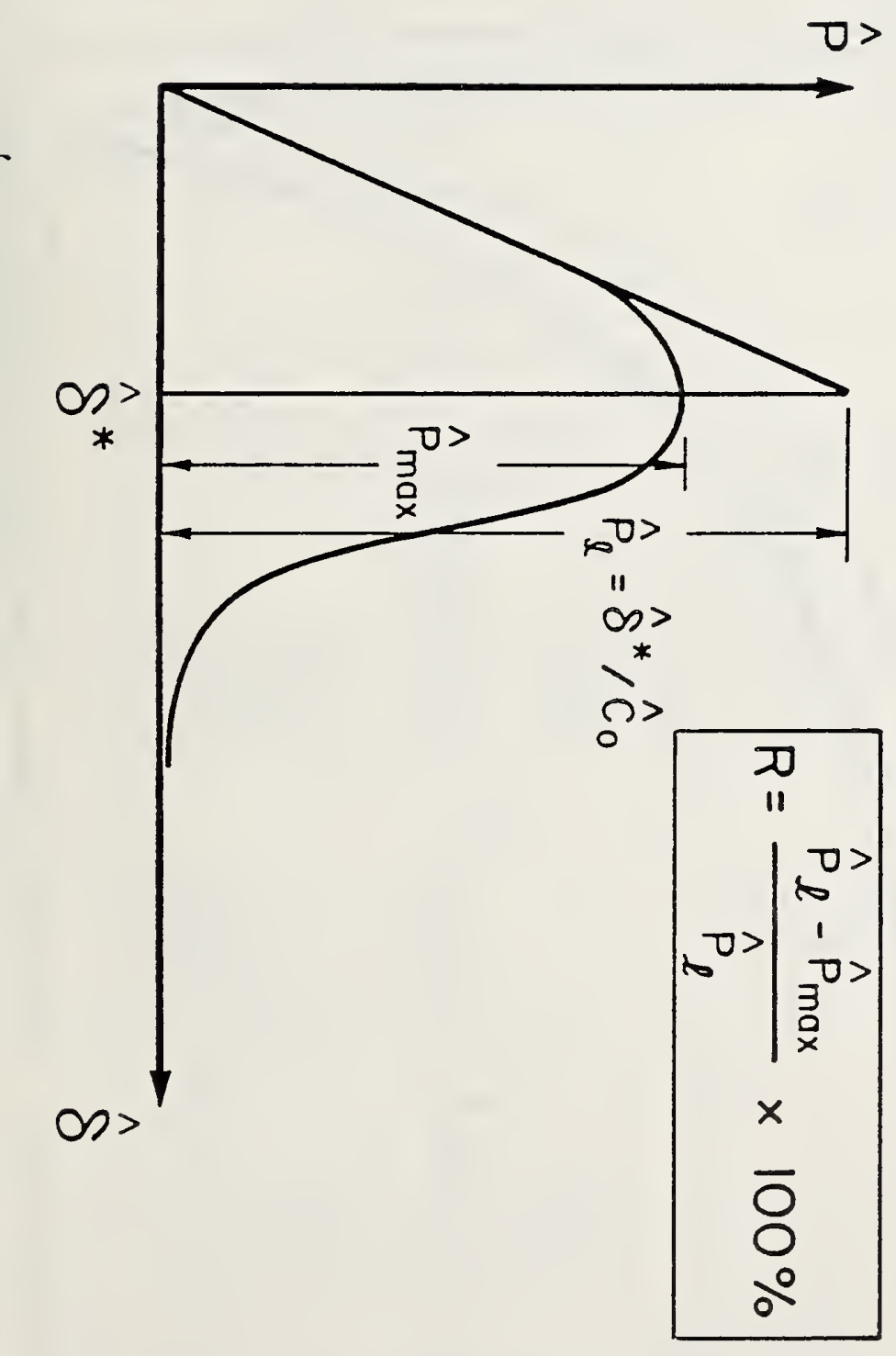




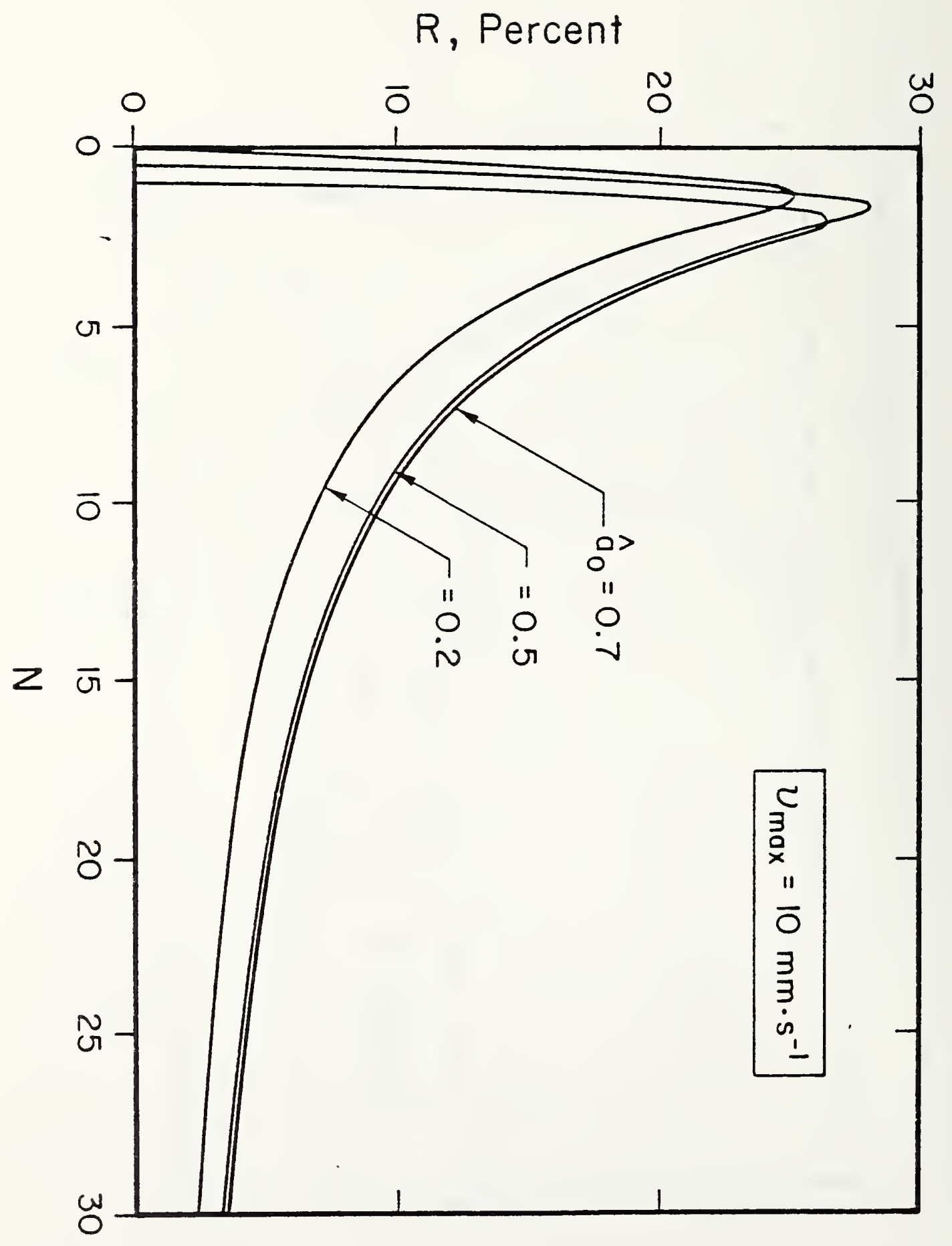




\section{START}

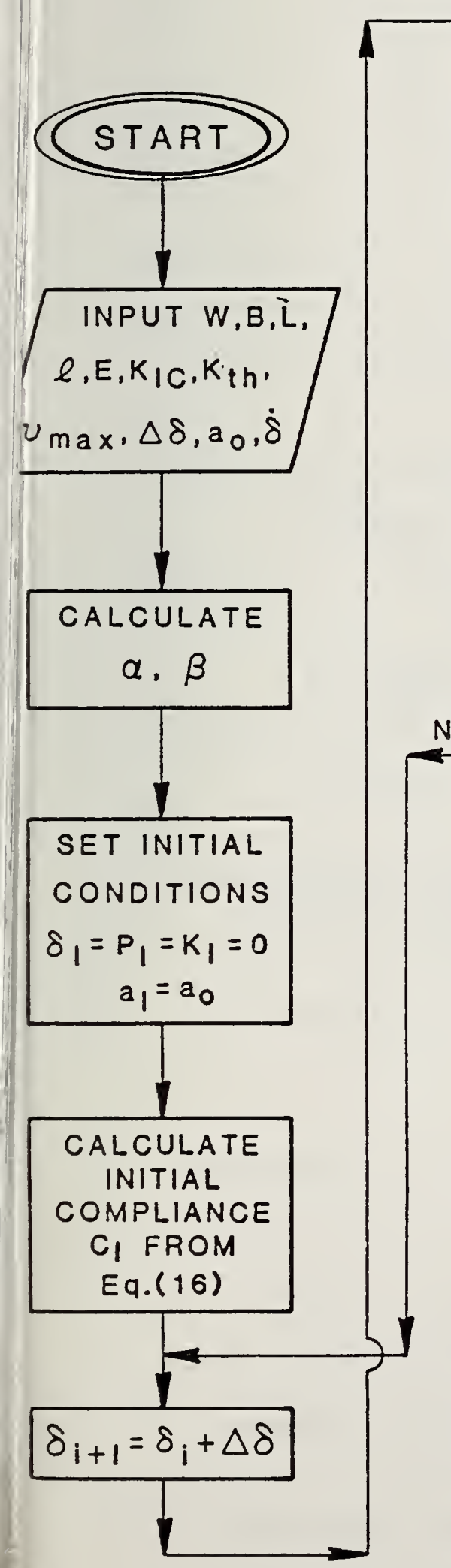

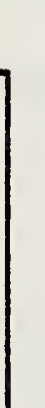

No RANGE WITHOUT CRACK GROWTH $P_{i}=\delta_{i / c_{1}}, K_{i}=$
$P_{i} Y\left(a_{1}\right)$
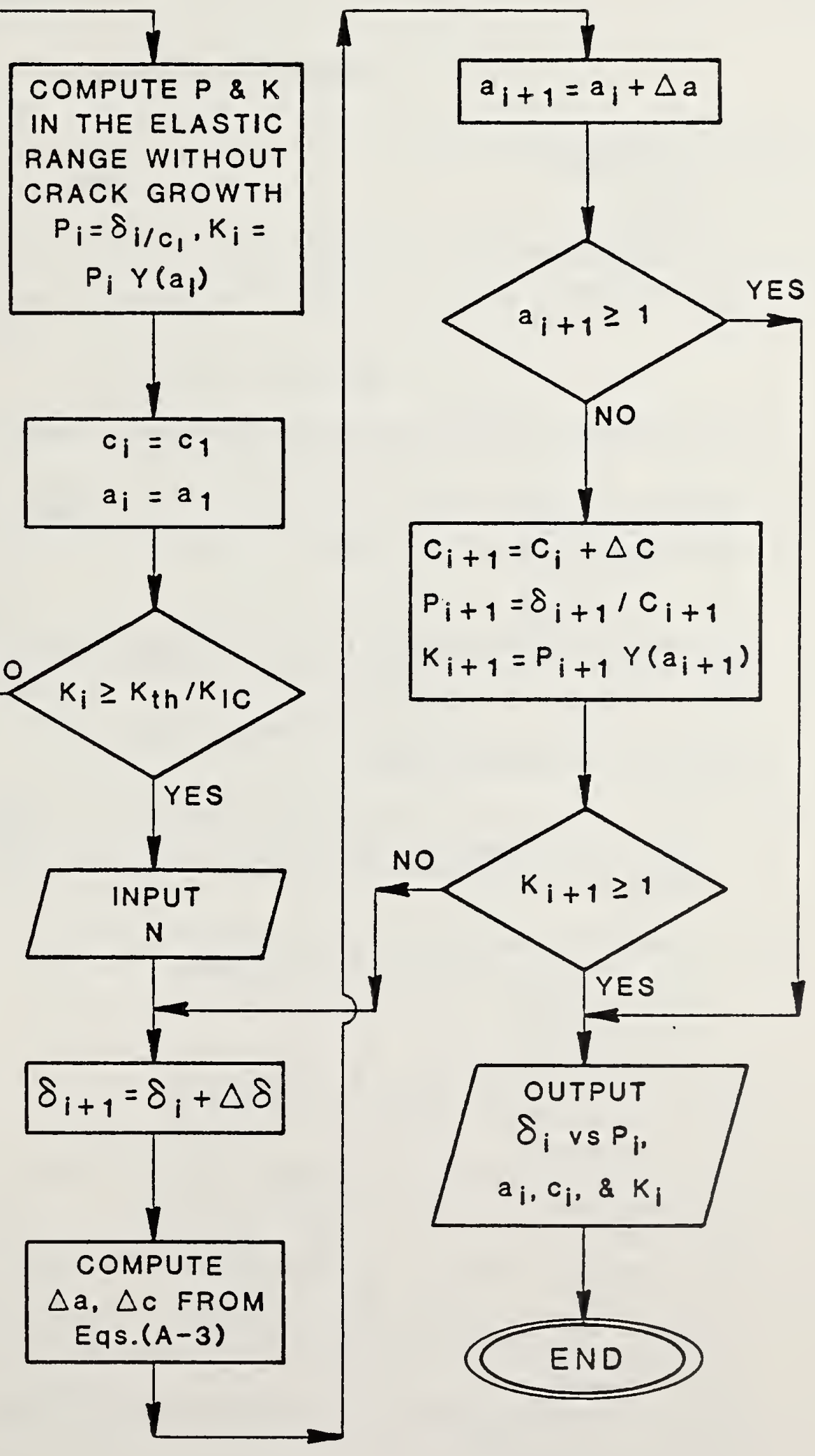
NBSIR $82-2504$

INTERNAL DISTRIBUTION

1. E. R. Fuller, Jr.

2. S. J. Schneider, Jr.

3. R. P. Reed

4. N. J. Tighe

5. J. B. Wachtman, Jr.

6. S. M. Wiederhorn

\section{EXTERNAL DISTRIBUTION}

7. Ames Laboratory, Iowa State University, Ames, Iowa 50011 0 . Buck

8-10. Argonne National Laboratory, 9700 S. Cass Avenue, Argonne, Illinois 60439

W. A. Ellingson

C. R. Kennedy

D. S. Kupperman

11. Battelie Columbus Laboratories, 505 King Avenue, Columbus, Ohio 43201

I. G. Wright

12. Bureau of Mines, Tuscaloosa Research Center, P.O. Box I, University, Alabama 35486

H. Heystek

13-14. Cornell University, Materials Sciences and Engineering Department, Bard Hall, Ithaca, NY 14853

C. - Y. Ii

R. $R a j$

15-17. Electrical Power Research Institute, 3412 Hillview Avenue,

P.0. Box 10412, Palo Alto, CA 94303

W. T. Bakker

R. I. Jaffee

$J$. Stringer

18. Exxon Research and Engineering Company, P.O. Box 101, Florham Park, New Jersey 07932

E. M. Anderson

19. Gas Research Institute, 8600 West Bryn Mawr Avenue, Chicago, Illinois 60631

V. L. $\mathrm{Hill}$

20. IIT Research Institute, 10 West 35th Street, Chicago, IIlinois 60616 S. A. Bortz

21. Lawrence Berkeley Laboratory, University of California, Berkeley, California 94720

A. G. Evans

22. Metal Properties Council, Inc., United Engineering Center, 345 E. 47 St., New York, NY 10017

A. O. Schaefer 
23. National-Science Foundation, Division of Materials Research, Washington, DC 20550

B. A. Wilcox

24-27. Oak Ridge National Laboratory, P.O. Box X, Oak Ridge, Tennessee 37830

P. F. Becher

R. A. Bradley

P. T. Carlson

V. J. Tennery

28. Pennsylvania State University, College of Earth and Mineral Sciences, University Park, PA 16802

R. C. Bradt

29. Pennsylvania State University, Department of Materials Science and Engi-neering, University Park, PA 16802

30. Southwest Research Institute, 6220 Culebra Road, P.0. Drawer 29510, San Antonio, TX 78284

$31=$ F. F. Lyle, Jr.

-32. Virginia Polytechnic Institute and State University, Blacksburg, VA 24601

J. J. Brown, Jr.

D. P. H. Hasselman

33-34. DOE, Office of Fossil Energy, 20 Massachusetts Avenue, NW Washington, DC 20545

S. J. Dapkunas

J. Fairbanks

35. DOE, Office of Basic Energy Sciences, 20 Massachusetts Avenue, NW Washington, DC 20545

L. Ianniello

36-37. DOE, Oak Ridge Operations Office, P.O. Box E, Oak Ridge, Tennessee 37830

E. E. Hof fman Assistant Manager, Energy Research and Development

38. Technical Information Center, P.0. Box 62, Oak Ridge, Tennessee 37830 
BIBLIOGRAPHIC DATA

SHEET (See in structions)

4. TITLE AND SUBTITLE

Effectsof crack growth on the load-displacement characteristics of precracked specimens under bending

\section{AUTHOR(S)}

T.-J. Chuang, E. R. Fuller, Jr., R. J. Fields, and L. Chuck

6. PERFORMING ORGANIZATION (If joint or other than NBS, see in structions)

MATIONAL BUREAU OF STANDARDS

DEPARTMENT OF COMMERCE

WASHINGTON, D.C. 20234

9. SPONSORING ORGANIZATION NAME AND COMPLETE ADDRESS (Street, City, Stote, ZIP)

7. Contract/Grant No.

DE-A105-800R20679

Department of Energy

Advanced Research \& Technology Development

Fossil Energy Materials Program

Washington, DC 20545

10. SUPPLEMENTARY NOTES

Document describes a computer program; SF-185. FIPS Software Summary, is attached.

11. ABSTRACT (A 200-word or less foctual summary of most significont information. If document includes o significant bibliography or literature survey, mention it here)

A critical evaluation of the feasibility of obtaining crack growth parameters from bend tests is presented. First derived are the governing differential equations which characterize the time-history of bend test parameters for a given elastic material exhibiting power law crack growth behavior. A numerical solution scheme is then developed which is capable of solving the initial value problem, thus quantitatively assessing the influence of crack growth on the load-displacement output. The results of this analysis indicate that for high $\mathrm{N}$ materials (where $\mathrm{N}$ is the exponent in the power law crack growth equation) the flexural test method gives a broad error band in $N$ prediction and hence is not a reliable technique. However, it can be used by a designer to quickly screen the new materials with high $\mathrm{N}$ values which are potential candidates for structural application.

12. KEY WORDS (Six to twelve entries: alphabetical order: capitalize only proper names; and separate key words by semicolons) Ceramic fracture test; crack growth of ceramics, four-point bend test; fracture test; initial value problem; load-displacement characteristics; power-law crack growth.

13. AVAILABILITY

X Unlimited

For Official Distribution. Do Not Release to NTIS

Order From Superintendent of Documents, U.S. Government Printing Office, Washington, D.C. 20402.

X Order From National Technical Information Service (NTIS), Springfield, VA. 22161
14. NO. OF PRINTED PAGES

39

15. Price

$\$ 7.50$ 
$-$

$-$ 
